Brit. F. vener. Dis. (1971) 47, 36

\title{
Treatment of trichomoniasis in the female with a 5-day course of metronidazole (Flagyl)
}

\author{
A. N. MCCLEAN \\ Lydia Department, St. Thomas' Hospital, London
}

Over a period of 10 years very satisfactory results have been obtained in the treatment of trichomoniasis in women with a 7-day course of 'Flagyl' at a dosage of $200 \mathrm{mg}$. three times a day, without any concomitant local therapy (Rodin, King, Nicol, and Barrow 1960). In view of the known unreliability of patients in following any dosage schedule, it was felt that a simpler and shorter regimen would be advantageous, if it proved equally effective.

\section{Method}

A trial was carried out with a dosage of two tablets (400 mg.) twice daily for 5 days. This gives a total dosage of $4 \mathrm{~g}$. compared with $4.2 \mathrm{~g}$. by the former schedule. The initial diagnosis was made by a wet smear or culture and a 3 month follow-up with tests by the same procedures was aimed at in each case.

\section{Material}

200 female patients with first infestations with Trichomonas vaginalis were treated at the clinic at St. Thomas' Hospital. Their ages ranged from 13 to 55 years (mean 26). There were 120 single women, 59 married, fifteen separated, five divorced, and one widowed.

\section{Results}

Of the 200 patients, 198 completed the course of $400 \mathrm{mg}$. Flagyl twice daily for 5 days. Of the remaining two patients, one developed an urticarial rash (the only recorded toxic effect in this series)

Received for publication July 23, 1970. and treatment was stopped after 2 days, and the other admitted to intermittent dosage when the infection was found to have persisted. After a second course taken correctly a cure was effected. No patients defaulted immediately after a first course of treatment, although many did not complete the full 3 months' follow-up; a high proportion attended for one set of post-treatment tests only (Table I).

TABLE I Completion of course of treatment

$\begin{array}{llll}\text { No. of patients } & \begin{array}{l}\text { Completed first } \\ \text { treatment }\end{array} & \begin{array}{l}\text { Immediate } \\ \text { defaulters }\end{array} & \text { Nil }\end{array}$

In 181 of these 198 cases there was apparent cure, but a full 3 months' follow-up was completed in only 26 cases (Table II). In seventeen cases the parasite was still detected after completion of treatment; these are analysed to show the interval between treatment and the reappearance of $T$. vaginalis and whether or not the patient admitted to further sexual intercourse (Table III).

These cases are also divided into those in which the failure was immediate, with the parasite showing on the first post-treatment test, and those in which there were one or more intervening negative results before $T$. vaginalis reappeared (Table IV). Eight of the seventeen cases of failure or re-infection continued to attend for follow-up and responded to re-treatment with the same dosage of metronida-

TABLE II Apparent cures with length of follow-up

\begin{tabular}{|c|c|c|c|c|c|}
\hline Duration of follow-up (mths) & Less than 1 & $1-2$ & $2-3$ & More than 3 & Total \\
\hline No. of patients & 77 & 49 & 29 & 26 & 181 \\
\hline
\end{tabular}

TABLE III Investigation of seventeen treatment failures

Duration of follow-up (mths)

\begin{tabular}{llll}
\hline Less than 1 & $\frac{1-2}{2}$ & $\frac{2-3}{4}$ & $\frac{\text { More than } 3}{3}$
\end{tabular}

\section{Further sexual intercourse}

\begin{tabular}{lll} 
Admitted & Denied \\
\hline 11 & $?$ \\
\hline
\end{tabular}


TABLE IV Analysis of seventeen treatment failures

\begin{tabular}{|c|c|c|c|c|c|c|}
\hline \multirow{2}{*}{ Time of assessment } & \multicolumn{2}{|c|}{ Failures } & \multicolumn{2}{|c|}{ Successes } & \multicolumn{2}{|c|}{ Total } \\
\hline & No. & Per cent. & No. & Per cent. & No. & Per cent. \\
\hline Immediately after treatment & 2 & $1 \cdot 0$ & & & & \\
\hline Later & 15 & $7 \cdot 6$ & 181 & $91 \cdot 4$ & 198 & 100 \\
\hline Total & 17 & $8 \cdot 6$ & & & & \\
\hline
\end{tabular}

zole. The remaining nine patients defaulted immediately after re-treatment.

Thus, of 198 cases treated, there was apparent cure in 91.4 per cent., and among the seventeen cases in which the parasite was detected after treatment there was a probability of re-infection in at least eleven cases.

\section{Summary}

Two hundred women with vaginal trichomoniasis were treated with metronidazole $400 \mathrm{mg}$. twice daily for 5 days to discover whether this shorter and simpler dosage was as effective as the customary regimen of $200 \mathrm{mg}$. three times a day for 7 days. 198 women completed their treatment and underwent at least one examination for cure. Failure or re-infection was detected in seventeen cases ( 8.6 per cent.) but in at least eleven of these there was reason to presume further exposure to risk. This trial indicates that metronidazole is effective in this easier dosage regimen.

The author gratefully acknowledges the help and advice of Dr. C. S. Nicol, Senior Consultant in Venereology, and Dr. J. Barrow, Consultant in Venereology, at St. Thomas' Hospital, in the preparation of this paper.

Note: A 400-mg. tablet of metronidazole will become available from May and Baker.

\section{Reference}

Rodin, P., King, A. J., Nicol, C. S., and Barrow, J? (1960) Brit. F. vener. Dis., 36, 147 